\title{
Green Tea: A Potential Alternative Anti-Infectious Agent Catechins and Viral Infections
}

\author{
Jennifer Tran \\ University of North Carolina at Chapel Hill, Chapel Hill, USA \\ Email: tranj@email.unc.edu \\ Received February $14^{\text {th }}, 2013$; revised March $17^{\text {th }}, 2013$; accepted April $13^{\text {th }}, 2013$
}

\begin{abstract}
Copyright $(\underset{2}{ } 2013$ Jennifer Tran. This is an open access article distributed under the Creative Commons Attribution License, which permits unrestricted use, distribution, and reproduction in any medium, provided the original work is properly cited.
\end{abstract}

\begin{abstract}
Tea is the second most consumed beverage in the world, following water. Black, oolong, and green tea are products of a perennial tree or shrub called Camellia sinensis. Camellia sinensis is native to Mainland China and is referenced in Chinese literature at least 5000 years ago. Since its discovery, green tea has been heralded as having several health benefits associated with its consumption. Traditionally, green tea has been used for a variety of medicinal purposes, such as the prevention and treatment of a variety of cancers, mental alertness, weight loss, lowering cholesterol level, and UV protection. Studies have shown that catechins, the polyphenols found in tealeaves, are effective as anti-infectious agents by affecting the infection process instead of specifically targeting the virus. This treatment strategy has the potential of reducing the prevalence of drug-resistant viruses and the reliance on anti-viral drug therapies. This paper will explore the efficacy of green tea in preventing infections by the hepatitis B and C, influenza and human immunodeficiency virus.
\end{abstract}

Keywords: Catechins; Viral Infections; Green Tea; Camellia Sinensis; HIV; Influenza; Hepatitis; Ancient China; Coevolution; Phytochemicals; Phenols

\section{Introduction}

Tea is a widely consumed beverage worldwide. In order for something to be considered a tea, the beverage must be produced from the leaves of the evergreen plant, Camellia sinensis, which is a member of the Thaceae family. Black, oolong, and green tea are brews of this plant, but vary in their processing method and degrees of fermentation and oxidation. Steaming fresh leaves produces green tea, which results in the preservation of the color (hence the name) and in the highest concentrations of antioxidants in a tea. Studies have shown that the positive health benefits of green tea may be due to these antioxidants (also known as catechins, the tea polyphenols).

Green tea is widely popular in East Asia (particularly in China and Japan), whereas, black tea is the preferred tea in the West. But green tea's popularity is increasing and is being consumed by more people worldwide due in part to increasing awareness of the many health benefits that green tea is said to have as concluded by many scientific studies on this subject (Random History, 2008).

\section{Ancient China}

In Chinese history, the consumption of green tea has been referenced as far back as the third century B.C. But according to Chinese folklore, the beginnings of the tea culture began around 2737 B.C. (Cultural China 2007-2010). The process of brewing the tealeaves in hot water was discovered accidentally by the second Emperor of China, Shen Nung. Shen Nung, also an herbalist who studied plants and herbs, was in the courtyard of his palace boiling water in order to safely drink it when a breeze stirred the branches of a tree causing the leaves to drop into his pot of boiling water. Shen Nung found the combination to be refreshing and stimulating, and thus the Chinese tea culture began.

Tea was consumed primarily for its medicinal properties. As an herbal medicine, Camellia sinensis leaves were added to food to provide nutrients and also used as an antidote for poison (Cultural China, 2007-2010). Chinese people prefer to drink tea after their meals to take advantage of its benefits in aiding digestion. It was also used to increase alertness and alleviate the effects of depression and nervous conditions (Random History, 2008).

The first written reference to the consumption of tea was in 350 A.D. in a Chinese dictionary (Cultural China, 2007-2010). During the Tang Dynasty (618-907 A.D.), tea cultivation and trade increased leading to a period considered the "golden age" of tea, which is also when tea drinking evolved into an art form (Cultural China, 2007-2010). In 780 A.D., Lu Yu wrote a book called Ch'a Ching, or the Tea Classic, that outlined how to grow and cultivate the plant, how to brew the tea and how to perform a complicated formal tea ceremony that involved twenty-seven pieces of equipment (Cultural China 2007-2010). The complexity of the ceremony limited it to wealthy individuals such as scholars, officials, and members of the royal court. The manual became the standard for cultivation and production in China, and eventually became the foundation of a tea ceremony that emerged in Japan (Moxham, 2003). It was also during the Tang Dynasty that other flavors, such as jasmine and lotus, 
were being incorporated in the brew (Random History, 2008).

Tea remained costly and was limitedly available to royalty until the fall of the Mongolian empire in 1368 A.D. (Green Tea Earth, 2010). As tea cultivation and trade increased, the beverage became more available to members of every class. For example, Chinese seamen drank green tea for its high amount of vitamin $C$ that warded off scurvy and Buddhists chewed the leaves to help them with their meditation (Green Tea Earth, 2010). People have found that by drinking tea, their health had improved, their emotions were soothed, and their perceptions were heightened (Cultural China, 2007-2010). Tea also became an economic and political tool utilized by China via trade throughout mainland Asia (Cultural China, 2007-2010). Compressed tealeaves were used as currency to barter (i.e. for horses) and kept the Chinese army mobile.

Between 729 and 800 A.D., green tea arrived in Japan (Green Tea Earth, 2010). Emperor Shōmu, the $45^{\text {th }}$ Emperor of Japan, gave powdered green tea as gifts to Buddhist monks. In Japan, the teas Sencha (green tea made from un-ground leaves), Matcha (green tea made from powder) and Bancha (green tea made from leaves harvested between summer and autumn) were first introduced with varying processing levels of the leaves that had harvested at different times (Green Tea Earth 2010). The tea ceremony became an important practice in Japan that reflected their desire for peace and harmony.

Because of China's economic superiority and self-sufficiency, they were able to limit trade to Canton and prohibit Europeans from entering and communicating with Chinese merchants (Cultural China, 2007-2010). Tea was introduced to the West in 1606, with the first shipment to Europe being green tea (Green Tea Earth, 2010). Tea became popular in Europe and was in high demand in the eighteenth century, but China was able to deny them access to the product. In response, Europeans introduced opium to the Chinese resulting in a deficit in China's economy in the mid-1800s, forcing the country to open the country to foreign trade (Cultural China, 2007-2010).

\section{Tea Culture}

Food that defines a culture often has enhancement properties. Green tea is especially popular in East Asia, particularly in China and Japan. The Chinese have a saying that translates into, "Firewood, rice, oil, salt, sauce, vinegar and tea are the seven necessities to begin a day" (Travel China Guide, 1998-2012). Tea is mentioned because it is an important beverage and a source of water in Chinese culture. Another phrase used is " $\mathrm{Cu}$ Cha Dan Fan", which is used to describe a simple meal and translates to "coarse tea and tasteless dinner." (Travel China Guide, 1998-2012) These phrases emphasize the importance and prevalence of tea in Chinese daily life.

Green tea is not treated simply as something to be consumed but is also an art form with symbolic references. The tea process is well-defined by the Tea Classic, from its cultivation to its consumption. Tea and tea wares (teapots, teacups, and tea sets) should match surrounding elements, which underlies the ultimate goal of Chinese culture of harmonious unity of human beings with nature (Travel China Guide, 1998-2012). Tea also has been compared to personal characteristics to describe taste and fragrance, and is a symbol of elegance. Regarded as the most Zen-like drink, tea has a unifying characteristic that produces a feeling of calmness and eliminates inequalities between individuals when sharing a cup of tea (Travel China Guide,
1998-2012). It is described as a beverage of opposites, while still creating harmonious combinations; it is spiritual and material, invigorating and pacifying (Travel China Guide, 19982012).

As other people are introduced to and incorporate green tea into their lives, a unique tea culture is formed. In Japan, there is a rigorous tea ceremony called chanoyu which emerged during the twelfth century that reflects the nation's character of making full use of every resource (Travel China Guide, 1998-2012), and evolved to become "a precise pattern of behavior designed to create a quiet interlude during which the hosts and guests strive for spiritual refreshment and harmony with the universe" (Pettigrew, 2004). The goal of the tea ceremony is to promote world peace through a spiritual cultivation that encourages simplicity and humility (Sen, 1998; Random History, 2008). In the West, tea may be consumed with sugar and milk and served with desserts to create a leisurely and romantic atmosphere (Travel China Guide, 1998-2012).

Although varying tea-drinking habits exist, it is obvious that tea is enjoyed worldwide and has meaning and value to each culture despite how long tea has been present in that region. Green tea is becoming more well known for its medicinal properties and can be consumed in a variety of ways to take advantage of them, such as, in a beverage, in food products enhanced with tea catechins, or in concentrated capsules.

\section{Catechins}

Phytochemicals are biologically active compounds found in plants. Catechins are the bioactive compounds found specifically in the leaves of Camellia sinensis. With increasing specificity, catechins can be defined as phytochemicals, polyphenols, flavonoids, and tannins.

Polyphenols describes the chemical compound structure of having several hydroxyl functional groups $(-\mathrm{OH})$ attached to an aromatic hydrocarbon group (Xie et al., 2012). Categorized as secondary metabolites, polyphenols can also be divided into smaller subgroups. One subgroup of polyphenols is flavonoids, which has its own subdivision of flavanol monomers (or catechins). Phenols are widely spread throughout the plant kingdom, which suggests a beneficial adaptation had occurred early in human and plant history that was naturally selected for. It also suggests that there exists a long coevolutionary history between phenolic acids and the consumers of plants that contain them.

Phenols are essential for the fitness of the plants (i.e. growth and reproduction) and are produced as a defense response against pathogens. Recent interests in phenolic compounds stem from their potential protective role against oxidative damage diseases (coronary heart disease, stroke, and cancers) and its possible utility as a natural antioxidant.

Catechins are antioxidants that scavenge for free radicals that can damage DNA, change the cell, cause cell death, and contribute to cancer, blood clots and atherosclerosis (University of Maryland Medical Center, 2011). These compounds may be able to do this by neutralizing free radicals and reducing or even helping prevent some of the damage they cause. Catechins are more concentrated in green tea due to its minimal processing. They make up approximately $30 \%$ to $40 \%$ of the dry weight of green tea leaves (Molinari et al., 2006). Some of the primary catechin compounds include epicatechin, epigallocatechin, epicatechin-3-gallate, and epigallocatechin gallate (EGCG) (Molinari et al., 2006). Epigallocatechin gallate is the most 
studied and most active catechin in green tea. It makes up approximately half of the total catechins (University of Maryland Medical Center, 2011). EGCG is the main active ingredient in green tea leaves and has a molecular formula of $\mathrm{C}_{22} \mathrm{H}_{18} \mathrm{O}_{11}$ (Umashankar, 2001).

\section{Health Effects and Benefits}

Green tea has many well-known effects and benefits. It has anti-diabetic, hypocholesterolemic, anti-inflammatory, anti-carcinogenic, anti-cavity, thermogenic, probiotic, antimicrobial and antiviral properties (Song \& Seong, 2007; Molinari et al., 2006).

Population-based and in vitro studies have been conducted to show that catechins may help kill cancerous cells and stop their aberrant growth in bladder, breast, ovarian, colorectal, esophageal, lung, pancreatic, prostate, and skin cancer (University of Maryland Medical Center, 2011).

Green tea's antimicrobial properties are effective against a variety of microbes, which include Helicobacter pylori (gastric malignancy), Staphylococcus aureus (MRSA), Oral streptococci (dental caries), Mycobacterium tuberculosis (tuberculosis), Bacillus cereus (food poisoning), Escherichia coli 0157 (severe diarrhea and kidney failure), Legionella pneumophila (pneumonia), Candida albicans (candidiasis), and Chlamydia trachomatis (chlamydia) (Song \& Seong, 2007).

Its antiviral properties are effective against HIV, influenza, Epstein-Barr, Herpes, Hepatitis B and C, and Human T-cell lymphotropic virus type 1 (HTLV-1; leads to adult T-cell leukemia) (Song \& Seong, 2007; Xu et al., 2008; Ciesek et al., 2011). Because the use of antiviral drugs can cause the emergence of drug-resistant viral strains, the cultural adoption of green tea consumption appears to be a potential effective antiinfection agent with minimal (if any) negative consequences.

\section{Materials and Methods}

For this paper, I used the PubMed search engine to find and analyze studies designed to determine the effect that phytochemicals extracted from green tea had on various infections. I narrowed my selection by reviewing papers that focused on viral infections, and that were conducted as either a population or in vitro study using human cells. The studies I selected were published between 2008 and 2011.

\section{Hepatitis $B$ and $C$}

Hepatitis is the irritation and inflammation of the liver due to a viral infection. The Hepatitis B virus (HBV) is endemic in Asia (Xu et al., 2008). An in vitro study conducted by Xu et al. (2008) involved the combination of natural green tea extract with an HBV cell line (HEPG2-N10) to determine the 50\% effective concentration on the expression of viral antigens (HBsAg and HBeAg), extracellular HBV DNA and intracellular replicative intermediates and nuclear covalent closed circular DNA, and HBV mRNAs. The study yielded results for the $50 \%$ effective concentration of green tea extract on $\mathrm{HBsAg}$ $(5.02 \mu \mathrm{g} / \mathrm{mL}), \mathrm{HbeAg}(5.681 \mu \mathrm{g} / \mathrm{mL})$, extracellular HBV DNA $(19.81 \mu \mathrm{g} / \mathrm{mL})$ and intracellular HBV DNA $(10.79 \mu \mathrm{g} / \mathrm{mL})$. The authors concluded that green tea extract and EGCG in particular inhibits the Hepatitis $\mathrm{B}$ virus in vitro.

The Hepatitis C virus (HCV) is a major cause of liver cirrhosis and hepatocellular carcinoma (Ciesek et al., 2011). Another in vitro study conducted by Ciesek et al. (2011) combined 100 $\mu \mathrm{M}$ of epigallocatechin-3-gallate (EGCG) to a medium of infected cells (hepatoma cell lines and primary human hepatocytes). EGCG was identified as an inhibitor of HCV entry by inhibiting infectivity of $\mathrm{HCV}$ during inoculation and disrupting the initial step of HCV cell entry by inhibiting viral attachment to the cell.

\section{Influenza}

Influenza is due to the infection of the respiratory system (nose, throat, and lungs) by RNA viruses. Evidence has been found to suggest that catechins, especially EGCG, have virucidal effects on all three major human influenza viruses (A/H1N1, A/H3N2 and B) (Song et al., 2005).

In a population-based study of schoolchildren in Kikugawa City, Japan, Park et al. (2011) distributed an anonymous questionnaire survey twice during the 2008-2009 endemic type A influenza season to 2050 elementary school students in a tea plantation area in Japan. The age range of the participants was 6 to 13 years old. The study found that an adjusted odds ratio inversely associated with consumption of 1 cup/day to $<3$ cups/ day was .62 in cases of confirmed influenza by the antigen test, and that associated with consumption of 3 - 5 cups/day compared with $<1 \mathrm{cup} /$ day was .54 . There was no significant assumption with the consumption of $>5$ cups/day. Therefore, Park et al. (2011) concluded that the consumption of 1 - 5 cups/day of green tea might prevent influenza infection in children.

A randomized, double blind placebo-controlled trial of 197 healthcare workers in three healthcare facilities for the elderly was conducted during the 2009-2010 influenza season in Higashimurayama, Japan by Matsumoto et al. (2011) The participants were divided into two groups: green tea catechins/theanine $(\mathrm{N}=98)$ and control $(\mathrm{N}=99)$. The first group received capsules containing $378 \mathrm{mg}$ of catechins and $210 \mathrm{mg}$ of theanine to take daily. The control group received placebos. The incidence of clinically defined influenza infection and laboratory-confirmed influenza with viral antigen, and the time for which the patient was free from clinically defined influenza infection were measured. They found that 4 participants in the experimental group and 13 from the control group reported incidences of clinically defined influenza infection. On the other hand, only 1 of the experimental group and 5 from the control group had laboratory-confirmed influenza, which is statistically insignificant. Matsumoto et al. concluded that green tea catechins and theanine (an amino acid found naturally in green tea) might be effective prophylaxis for influenza infection among healthcare workers for the elderly.

\section{Human Immunodeficiency Virus (HIV)}

$\mathrm{HIV}$ is an infection caused by a lentivirus that incorporates the viral RNA sequence into the host genome by reverse transcription. It gradually destroys the immune system and causes acquired immunodeficiency syndrome (AIDS). Catechins have inhibitory effects throughout the infection life cycle. They compromise the physical integrity of the virion, bind to the host cells, blocking post-absorption entry, and prevent the replication of the viral genome by inhibiting reverse transcriptase (Pandey \& Rizvi 2009). EGCG has been found to bind directly to CD4 (the glycoproteins found on the surface of T lymphocytes), which consequently, inhibits gp120 binding.

One study conducted by Li et al. (2011) combined EGCG to 
HeLa-CD4-LTR-beta-gal cells. They found that the $50 \%$ effective concentration was relatively low $(1.6$ and $2.0 \mu \mathrm{M})$ for both HIV-1 (IIIB) and HIV-2 (EHO) infections. Using a time-ofaddition assay, it was determined that the inhibitory profile of EGCG was identical to that of a non-nucleoside reverse transcriptase inhibitor, MKC-442. When a nucleoside reverse transcriptase inhibitor, 3'-azido-3'-deoxythymidine or AZT, was also added to the cell culture, it was discovered that EGCG and AZT synergistically inhibited HIV infection. They concluded that EGCG might act mainly as an allosteric reverse transcriptase inhibitor (Li et al., 2011).

Another in vitro study was conducted by adding EGCG to peripheral blood mononuclear cell cultures. The study was done by Hauber et al. (2009) to determine if EGCG had an effect on semen-derived enhancement of HIV infection. Peptide fragments, derived from prostatic acidic phosphatase, are secreted in large amounts into human semen and form amyloid fibrils that capture HIV virions and direct them to target cells (Hauber et al., 2009). The study showed that EGCG targets semen-derived enhancer of virus infection (SEVI) for degradation, inhibits its activity and abrogates semen-mediated enhancement of HIV-1 infection in the absence of cellular toxicity.

\section{Concerns and Criticisms}

The consumption of green tea and its potential anti-infectious properties have been criticized for several reasons. The first is the cultural factors that may confound these studies. Because green tea is more widely consumed in East Asia, especially in China and Japan where the tea culture is well embraced, there is a worry that the link made between green tea catechins and its health benefits may actually be due to other cultural practices shared by these populations, such as another staple in their diet. Because studies have been conducted in human cell cultures, there is evidence to suggest that green tea catechins do provide these health benefits as a property of their catechins and that they may be amplified or isolated in certain cultures because of its green tea culture.

Another critique of catechins is its bioavailability to humans by drinking green tea. But through these studies presented, it appears that an individual could get several health benefits from drinking less than 5 cups of green tea daily, not only for green tea's invigorating, refreshing qualities but also as an aid in digestion, and prevention of viral infections and cancer.

As with all phytochemicals, there is a concern that excessive consumptions will have detrimental effects. Due to the obesity epidemic, there is an increasing interest in diet products and weight-less supplement, which include green tea extract packaged in pills. A case report conducted by Molinari et al. (2006) presented a 44-year-old female of European descent suffering from worsening acute liver failure. She was participating in a weight-loss program for 6 months that recommended increased physical activity and the intake of dietary supplements containing green tea extract with a concentration of $720 \mathrm{mg} /$ day. Reports like this one have shown a correlation between patients presented with marked liver toxicity in the form of acute heaptitis and the consumption of supplements containing green tea extracts. These cases of toxicity were limited to individuals and resolved after discontinuation of the supplementation (Molinari et al., 2006). This underlies the necessity for an increase in awareness and education of the use of supplementation. Based on a preliminary search, there are no studies that have presented any adverse consequences of drinking green tea suggesting that it is most likely safe to consume green tea as a beverage with little to no risk.

\section{The Coevolution of Humans and Plants}

The interactions between Camellia sinensis and humans have lasted for thousands of years and the strength of these interactions varies between cultures. As is self-evident, green tea has grown into a culture that encompasses many practices that range from its cultivation to its consumption in China. This relationship between humans and Camellia sinensis is highlighted by the numerous health benefits green tea is found to have. But this is only one aspect of their interconnected history.

The cultivation of Camellia sinensis has outlined the role of humans in the evolution of this species. Through artificial selection, certain traits have been selected for over time, which has led to less diversity within the species and a divergence genotypically and phenotypically of domesticates from their wild counterparts. Although the effect of humans over plants is much more apparent phenotypically, plants have an effect on humans, as well. The phytochemicals produced by plants must create an appeal for humans to invest the time and energy into the care of the plant.

Since its discovery, Camellia sinensis has been domesticated in a way that appealed to humans who chose certain mutations that they found desirable, which resulted in the increase in prevalence of particular mutated genes. These mutated genes are preserved in the species and encode proteins that may affect humans' own biology and behavior. Catechins are necessary for the plant's growth, reproduction, and defense; therefore, it is likely that the catechin level has increased over time because of its integration into the culture, for only the most resilient strains would have survived and been selected for by the cultivators. Also, green tea has been used for its medicinal properties almost immediately after its discovery. This purposeful use of green tea may have resulted in other behaviors in humans that led to the selection for plants with higher catechin levels.

As indicated by the Chinese manual, the Tea Classic, humans play an active role in determining when and where the plant should be grown and how it should be cultivated. The plant is most suitable to hot and humid climates and is cultivated in low rows for easy harvesting (Pettigrew, 2004). Although fermentation makes the export of tea easier, the unfermented version of tea remains the preferred tea in the East and is increasing in popularity in other parts of the world. This preference may be a result of humans' conscious or subconscious desire for catechins and their health benefits.

\section{Conclusion}

The consumption of green tea has a history that spans back to over 5000 years. Traditionally, it was prescribed for a number of ailments while also being consumed for its refreshing qualities and the prevention of future health problems. Starting in China, the green tea craze has expanded worldwide to become the second most consumed drink after water. This increase in popularity is in part due to the increasing awareness of green tea's many health benefits. Besides its soothing and invigorating capabilities, it is consumed for its anti-diabetic, hypocholesterolemic, anti-inflammatory, anti-carcinogenic, anti-cavity, antimicrobial and antiviral properties (Song \& Seong, 2007). 
The active ingredients in green tea that contributes to these properties are the phytochemicals called catechins, in particular epigallocatechin gallate, the main and most active catechins. Studies have shown that EGCG is effective in preventing infection by the hepatitis, influenza, and human immunodeficiency viruses. Because EGCG affects the viral infection process rather than targeting the virus specifically, drinking green tea may be a potential effective anti-infection agent without the negative consequences of anti-viral drugs/treatment that leads to the development of new drug-resistant strains and a constant need for the development of new drugs.

The education of people about the numerous benefits of drinking green tea may lead to the adoption of this practice by other cultures. The change is small and easy to do. Green tea is widely available and is often processed in a way that it is preserved for a great length of time. By making green tea more available outside of coffee shops, Chinese restaurants, and grocery stores, there is a potential for a cascading effect to occur resulting in many positive changes, such as the reduced reliance on commercial drugs, and the reduced incidence and prevalence rates in high cholesterol, diabetes, cancer, cavities, and infections. Green tea has great potential in improving the health of people worldwide. With its rapid increase in popularity, a healthier world may be on the horizon.

\section{Acknowledgements}

The author would like to thank the editors of this manuscript and the reviewers who contributed their time. The author would also like to acknowledge Dr. Fatimah Jackson for her guidance, support and assistance throughout the research process.

\section{REFERENCES}

Ciesek, S., von Hahn, T., Colpitts, C. C., Schang, L. M., Friesland, M., Steinmann, J., Manns, M. P., Ott, M. et al. (2011). The green tea polyphenol, epigallocatechin-3-gallate, inhibits hepatitis $\mathrm{C}$ virus entry. Hepatology, 54.6, 1947-1955.

http://onlinelibrary.wiley.com/d oi/10.1002/hep.24610/abstract http://dx.doi.org/10.1002/hep.24610

How important the tea was in ancient China? Cultural China, 20072010. http://history.cultural-china.com/en/183History5676.html

Edgar, J. Health benefits of green tea.

http://www.webmd.com/food-recipes/features/health-benefits-of-gre en-tea

(2011). Green tea. University of Maryland Medical Center. $\mathrm{http} / / /$ www.umm.edu/altmed/articles/green-tea-000255.htm

(2010). Green tea's history from China to now. Green Tea Earth. http://www.greenteaearth.com/2010/03/02/green-teas-history-from-c hina-to-now/

Hauber, I., Hohenberg, H., Holstermann, B., Hurnstein, W., \& Hauber, J. (2009). The main green tea polyphenol epigallocatechin-3-gallate counteracts semen-mediated enhancement of HIV infection. Proceedings of the National Academy of Sciences of the United States of America, 106.22, 9033-9038.

http://www.ncbi.nlm.nih.gov/pmc/articles/PMC2683882/

http://dx.doi.org/10.1073/pnas.0811827106

National Center for Complementary and Alternative Medicine. National Institute of Health (2012). Herbs at a glance: Green tea. http://nccam.nih.gov/health/greentea

Li, S., Hattori, T., \& Kodoma, E. N. (2011). Epigallocatechin gallate inhibits the HIV reverse transcription step. Antiviral Chemistry \&
Chemotherapy, 21.6, 239-243.

http://www.ncbi.nlm.nih.gov/pubmed?term=Epigallocatechin\%20gal late\%20inhibits\%20the \%20HIV\%20reverse $\% 20$ transcription $\% 20$ ste

http://dx.doi.org/10.3851/IMP1774

Matsumoto, K., Yamada, H., Takuma, N., Niino, H., \& Sagesaka, Y. M. (2011). Effects of green tea catechins and tehanine on preventing influenza infection among healthcare workers: A randomized controlled trial. BMC Complementary \& Alternative Medicine, 11.15. http://www.biomedcentral.com/1472-6882/11/15 http://dx.doi.org/10.1186/1472-6882-11-15

Molinari, M., Watt, K. D., Kruszyna, T., Nelson, T., Walsh, M., Huang, W. Y., Nashan, B., \& Peltekian, K. (2006). Acute liver failure induced by green tea extracts: Case report and review of the literature. Liver Transplantation, 12.12, 1892-1895. http://dx.doi.org/10.1002/lt.21021

Moxham, R. (2003). Tea: Addiction, exploitation, and empire. New York: Carroll \& Graf Publishers.

Pandey, K. B., \& Rizvi, S. I. (2009). Current understanding of dietary polyphenols and their role in health and disease. Current Nutrition and Food Science, 5, 249-263.

http://mail.benthamscience.com/cnf/sample/cnf5-4/D0004NF.pdf http://dx.doi.org/10.2174/157340109790218058

Park, M., Yamada, H., Matsushita, K., Kaji, S., Goto, T., Okada, Y., Kosuge, K., \& Kitagawa, T. (2011). Green tea consumption is inversely associated with the incidence of Influenza infection among schoolchildren in a tea plantation area of Japan. Journal of Nutrition, 141.10, 1862-1870.

http://jn.nutrition.org/content/141/10/1862.long http://dx.doi.org/10.3945/jn.110.137547

Pettigrew, J. (2004). The tea companion: A connoisseur's guide. Philadelphia: Running Press.

Sen, S. (1998). The Japanese way of tea: From its origins in China to Sen Rikyū. Honolulu: University of Hawaii Press.

Song, J. M., Lee, K. H., \& Seong, B. L. (2005). Antiviral effect of catechins in green tea on influenza virus. Antiviral Research, 68, 66-74. http://jivasupplements.org/articles/Antiviral_effect.pdf http://dx.doi.org/10.1016/j.antiviral.2005.06.010

Song, J. M., \& Seong, B. L. (2007). Tea catechins as a potential alternative anti-infectious agent. Expert Review of Anti-Infective Therapy, 5.3, 497-506.

http://www.expert-reviews.com/doi/abs/10.1586/14787210.5.3.497? url_ver $=Z 39.88-2003 \& r f r \_i d=$ ori:rid:crossref.org\&rfr_dat $=$ cr_pub $=p$ ubmed http://dx.doi.org/10.1586/14787210.5.3.497

Tea culture. Travel China Guide. 1998-2012.

http://www.travelchinaguide.com/intro/cuisine drink/tea/culture.htm

The Green Tea Revolution-Ancient China, Japan, and Then the World (2008). Random history.

http://www.randomhistory.com/1-50/030tea.html

Umashankar, D. C. (2001). Quantitative and qualitative analysis of (-)epigallocatechin gallate from green tea by LC-MS. Journal of Natural Remedies, 1/2, 151-154.

http://indianforester.informindia.co.in/index.php/jnr/article/viewFile/ $27741 / 24036$

Xie, G., Zhao, A., Zhao, L., Chen, T., Chen, H., Qi, X., Zheng, X., Ni, Y. et al. (2012). Metabolic fate of tea polyphenols in humans. Journal of Proteome Research, 11.6, 3449-3457.

http://pubs.acs.org.libproxy.lib.unc.edu/doi/abs/10.1021/pr300318m http://dx.doi.org/10.1021/pr300318m

Xu, J., Wang, J., Deng, F., Hu, Z., \& Wang, H. (2008). Green tea extract and its major component epigallocatechin gallate inhibits heaptitis B virus in vitro. Antiviral Research, 78.3, 242-249. http://www.sciencedirect.com/science/article/pii/S016635420800029

http://dx.doi.org/10.1016/j.antiviral.2007.11.011 